\title{
A Sociolinguistic Approach to the Problem of Anglicisms in Armenian
}

\author{
Anahit Galstyan, Hayk Galstyan \\ Yerevan State University
}

\section{Introduction}

The methodological and theoretical foundations for researching attitudes were established in the parent disciplines of sociology and psychology in the first half of the twentieth century. Attitudes in general, and language attitudes in particular, are of considerable interest to social psychologists, sociologists and sociolinguists.

While reviewing studies in this field, we noticed that there is a great number of researches wherein the language attitudes of inhabitants from different bilingual settings within the same country are examined as well as transnational studies involving the majority and minority languages concerned in different bilingual areas (Ryan \& Giles1982; Baker1988; Edwards 1999; Garvett, Coupland \& Williams 2003; Giles \& Billings 2004; McKenzie 2010 and many others). However, attitudes towards English as a foreign language has been researched in a few studies (e.g. Lasagabaster, Huguet 2007). Besides, the attitude of Armenians towards the English language has not been examined yet.

Developing sociolinguistic theory has demonstrated that people's attitudes and perceptions towards language help to shape their usage, and these perceptions shape governmental and educational policy and language planning (Stockwell 2002:61). Hence,we aimed at carrying out a sociolinguistic as well as sociological study of purists' and ordinary native speakers' attitudes towards lexical enrichment of Armenian. Intelligibility and acceptability tests were made with young/old, town/country, educated/'backward' Armenian speakers from RA and from the USA, California (Los Angeles and Fresno). Our research in the USA was possible thanks to ESSE bursary 2009. The informants were mainly from Glendale and Hollywood (Los Angeles County), which are the cities where most of Armenian-Americans live. Glendale is home to 53,860 Armenian-Americans, making up $27.6 \%$ of the total population. As of 2009 , one out of five members of Glendale City Council was of Armenian descent - Ara J. Najarian. Former ArmenianAmerican mayors of Glendale were, Larry Zarian, Bob Yousefian, Rafi Manoukian, and AraNajarian. Armenian families have lived in the city since the $1920 \mathrm{~s}$, but the surge in immigration escalated in the 1970s. Armenian-Americans are well integrated into the city, with many businesses, several Armenian schools, and ethnic/cultural organizations serving this ethnic group. The research was also carried out in Fresno County, a melting pot of ethnic heritages and rich in cultural diversity. The population of Fresno County now exceeds 786,000 and includes Basque, Asian, Indian, Armenian, Hispanic, Chinese, Portuguese, and Japanese among its residents.

This visit enabled us to study the bilingual individual in a natural setting. In this context, 'minority language' is understood as the language spoken by a socially - and usually numerically - subordinate group within the total population of a given society. As stated in "Concise Encyclopedia of Pragmatics" (Mey 2009:44): 


\begin{abstract}
Language choice is not a purely linguistic issue. In many countries of the world, much of the social identification of individuals, as well as of groups, is accomplished through language choice. By choosing one or another of the two or more languages in one's linguistic repertoire, a speaker reveals and defines his or her social relationships with other people. At a societal level, whole groups of people, and in fact, entire nations, can be identified by the language and languages they use. Language, together with culture, religion, and history, is a major component of national identity.
\end{abstract}

In the USA we deal with a situation when a small weak language (in our case Armenian) comes into contact with a large powerful language (English) used by the majority or dominant group. The two languages in close contact can lead to interference in all aspects of language, from the sound system to conversational rules.

On the other hand, we have quite a different situation in the Republic of Armenia. After proclaming Independence from the USSR in 1991, Armenians ceased to consider Russian as lingua franca. Instead, English has become the main foreign language taught in schools and is used for the communication with the world, acquisition of technology and development at large. In order to be able to judge the validity of certain attitudes and evaluate the actual impact of English on Armenian both in the USA and RA, we have drawn information in two different ways: by questionnaires and interviews. Interviews provide a good deal of data, and are therefore invaluable in studying in depth the language attitude of the subjects. Interviews are much more flexible, but of course limited because of the time they take to give and analyze.

However, to obtain statistically analyzable data about attitudes and behaviors, a common technique is the questionnaire. The number of informants to those questionnaires in the Republic of Armenia was 564. The collection of the data and their sociolinguistic analysis took us a year (from 2010 to 2011). In the USA 320 people participated in our research, the results of which were compared and contrasted with the findings of our investigation in RA.

It should be noted that the same questionnaire was used and the same methodology was applied in each setting (in the USA and RA). By repeating the same question in different forms, we could get some idea of the reliability of the answers, and by careful wording of questions, attention was focused on those features that were to be analyzed.

One of the difficulties is that questionnaires are fixed in advance and so they might leave out questions that seem interesting later on. To eschew these shortcomings, we carried out a small-scale pilot study before the main survey. About 45 informants answered the questionnaires, which enabled us to make amendments in them.

The questionnaire utilized to gather the data can be divided into three main parts. The first one deals with personal information, such as age, sex, origin, etc. In the second section the participants are invited to answer questions concerning the use of Anglicisms in their speech. The final section touches upon the problem of improvement of the current situation and finding ways of struggle for the purity of our national language. 


\section{The Sociolinguistic Study}

As Hudson (1980:21) states, “....some linguistic items, such as items of vocabulary, are different from all other items with regard to the kind of person using them, or to the circumstances in which they are used". Thus we can assume that every individual in a community is unique in his language. Opinions, attitudes, and self-awareness of individuals and communities can affect linguistic usage. "Throughout history, people have altered their own language or forced others to change their language because of their own attitudes and beliefs" (Stockwell 2002:13).

This is the reason that we have tried to survey individual's attitude towards the use of Anglicisms in Armenian speech. The informants from RA and the USA have provided crucial information about the linguistic and extralinguistic factors that have contributed to the use and assimilation of Anglicisms in Armenian.

As mentioned above, the first part of the questionnaire (in Armenian) established the social background of the participants:

Males $-31.6 \%$ USA / $14.4 \%$ RA

Females $-68.4 \%$ USA / 84.6 RA

Permanent residence $-98 \%$ were the citizens of the USA. However, only $8.8 \%$ of them were born in the USA, whereas $77.5 \%$ were immigrants from the Republic of Armenia, $13.7 \%$ from other countries, such as Egypt, Iran, Lebanon, Syria. 2\% of informants were in the USA by educational projects or as temporary workers.

Why the number of the informants who were born in the USA is small can be explained by several factors: first, the estrangement of most third-generation Armenians (especially with roots in the Ottoman Empire and Mid-East), which is mainly the result of intermarriages as well as cultural assimilation. Most of these third-generation immigrants live outside the organized community in an institutional vacuum.

Second, the division of the Diaspora into two different groups: the older Diaspora (immigrants from 1920s to 1950s) and the new wave from Armenia.The several waves of Soviet emigration over the past 50 years have had a negative impact on the attitudes of older Diaspora, who have mostly distanced themselves from immigrants with Soviet lifestyle and mentality.

Rigorous analysis of the data collected in the current study has revealed that attitudes towards the use of English words in Armenian speech are considerably more complex than previously thought. $81.7 \%$ of Armenian-Americans think that the use of Anglicisms distorts our national language, whereas $8.7 \%$ admit that this is one of the means of enrichment of Armenian word stock; $3.8 \%$ believe that it is easier to understand the speaker when an Anglicism is used rather than it is translated or calqued; others perceive it as xenomania.

Grouping the answers and presenting them with the help of two variables: positive and negative, we shall have the following picture: $82.7 \%$ of Armenian-Americans and $49.5 \%$ of the citizens of RA consider it to be a negative phenomenon, $17.3 \%$ from the USA and $50.5 \%$ from RA believe it to be a positive one: $29.1 \%$ of RA participants think that Anglicisms contribute to the enrichment of the vocabulary of the Armenian language; $6.8 \%$ - do not find the use of Anglicisms blameworthy; 5.5\% - have positive 
attitude, but they are against the unnecessary application of Anglicisms in Armenian speech.

The outcomes revealed that the use of Anglicisms is not a problem among $23.1 \%$ of Armenians in the USA and $27.9 \%$ of RA citizens, while the majority of Armenians both in RA and abroad (68.2\% USA / 77.3\% RA) consider it to be a serious problem.

The informants are also asked whether there are elements or phenomena in their environment that contribute (encourage, stimulate) to the use of Anglicisms. The answers are as follows: $\quad 1$. Yes $-23 \%$ USA / $84.8 \%$ RA

\section{No $-46 \%$ USA / $9.1 \%$ RA}

3 . It is difficult to answer - $31 \%$ USA / $6.1 \%$ RA.

Informants were encouraged to give details and examples in addition to their "yes/no" answers. Hence, Armenian-Americans claim that the English environment, the lack of Armenian equivalents to English terms, or the lack of knowledge of the corresponding Armenian words contribute to the use of Anglicisms. On the other hand, most of the informants from RA believe that the main stimulating factor is xenomania; $36.4 \%$ consider it to be the Internet and the development of Information Technologies; $12.1 \%$ theestablishment of the English language as the global lingua franca.

We have also inquired about the domains, where the Anglicisms are often used.44.5\% of US residents and 56.1\% of RA citizens are sure that Armenian Mass Media (both in the USA and in the Republic of Armenia) are flooded with Anglicisms. $8.1 \%$ of Armenian-Americans use English words in clubs, 7.1\% - at home, 1.6\% - in Armenian Educational Institutions, whereas $11.5 \%$ from RA use English words with friends and relatives, $4.8 \%$ - in political parties, $2.9 \%$ - in Educational Institutions.

With respect to the importance given to the struggle against the use of Anglicisms in Armenian speech, the higher percentages refer to "very important" (70.3\% USA / 57.3\% RA), followed by "partially important" (16.2\% USA / 30.5\% RA), and finally"not important" (13.5\% USA / 12.2\% RA).

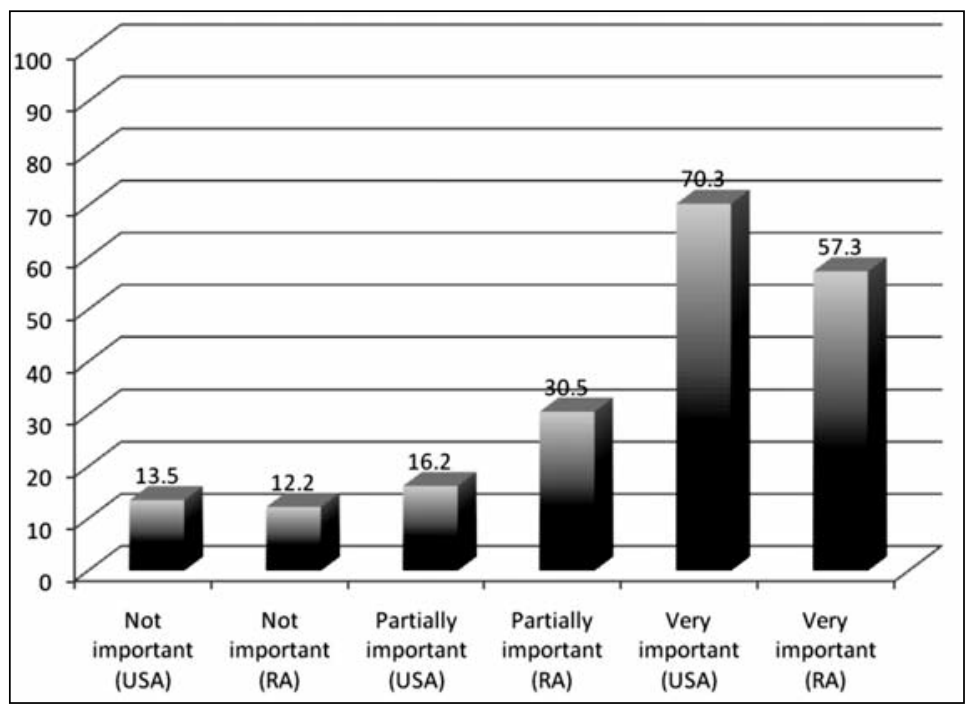


When analyzing the attitudes towards the purity of the national language, we observed that the percentage of more favorable attitudes was high: $57.7 \%$ of Armenians are sure that the struggle for the purity of Armenian is considered to be one of the main ways of maintenance of their national identity; $11.5 \%$ of participants think that this struggle will prevent the language from distortion and will contribute to the development of people's abilities to communicate in pure Armenian. Those who find this struggle as "partially important", mention that in certain situations the use of an English word becomes preferable. Unfavorable attitudes are very low in percentage: a small number of informants do not find it important to struggle for the purity of their national language and express an opinion that it is natural for Armenian-Americans to use English words, even to speak English instead of Armenian. They are sure that the citizens of RA should struggle for the purity of the language instead of the Diaspora. The mere fact that Armenian is still spoken by Armenian-Americans is considered to be a victory by some informants: "It's positive that you speak Armenian in the USA, it's a victory!" says one of the participants.

Several people in the Republic of Armenia think that in this globalizing world languages must be interlaced, and it is useless to struggle for the purity of the national language. $1.2 \%$ are convinced that people should struggle not against Anglicisms but against argo terms.

We found it striking that $87 \%$ of informants from the USA and $64.4 \%$ - from RA use Anglicisms in their speech. They mostly belong to the age-group 21-35.

Frequently applied Anglicisms by Armenian-Americans are: bill, bye, channel, check (anel), coffee, computer, date, excuse me, freeway, good, have a nice day, I love you, impression, insurance, lunch, no, OK, please, see you, sorry, stop (anel), thank you, TV, welcome, yes, all right, etc.

RA citizens often use the following English words: $O K, H i$, love, sorry, nice, of course, party, design, bank, fast food, good, maybe, online, of my god, super, hot-dog, bye, player, save, gentleman, office, mail, relax, message, file, credits, and many others.

To improve the current situation, the informants suggest:

1. perfecting the methods and means of teaching Armenian $-28.1 \%$ USA $/ 31.7 \%$ RA,

2. encouraging the use of Armenian in different spheres of life $-15.8 \%$ USA $/ 28.7 \%$ RA,

3. establishing a special institution for the struggle against the use of Anglicisms $11.8 \%$ USA / $6.5 \%$ RA,

4. creating conditions for the faultlessness of Armenian speech - 19.2\% USA/24.8\% RA,

5. lessening tolerance of Armenian speakers for the use of Anglicisms - 4.3\% RA,

6. leaving the question unsettled $-3.9 \%$ RA.

According to the analyzed data $44.2 \%$ of informants from the USA and $22.8 \%$ from RA claim that it will be immposible to do away with Anglicisms; that the use of the latters can be partially restricted $(31.7 \%$ USA $/ 42.3 \%$ RA); $15.4 \%$ of the US residents think that the number of Anglicisms in Armenian speech can be reduced, and only $1 \%$ USA residents and $1.9 \%$ RA citizens are sure that we can stop using Anglicims.

The outcomes revealed that the restriction of the use of Anglicisms in RA is mainly 
conditioned by the work of the following institutions: Language Inspectorate $(24.6 \%)$; Educational Institutions (16.2\% - schools, 9.6\% - Higher Educational Institutions); Mass Media (18\%); Ministry of Education of RA (7.8\%). Only $7.2 \%$ of RA citizens have mentioned the role of the family in the reduction of the number of Anglicisms in Armenian speech.

On the other hand, the Diaspora think that the struggle against the application of Anglicisms should be carried out in Armenian schools (23.6\%); in churches (10.2\%) and in families $(10.2 \%)$.

\section{Conclusion}

Contrasting our findings in the USA with the results of our survey in the RA we have come to the conclusion that Armenian-Americans are more interested in the purity of their national language than the informants living in RA.

We have also noticed some differences of attitudes between those informants who were born in the USA and the immigrants. Thus $4.3 \%$ of our compatriots born in the USA have "positive" attitude towards the use of Anglicisms in Armenian speech; $60.9 \%$ believe it to be a "negative" phenomenon; $34.8 \%$ - are indifferent to this problem.

Among Armenian-Americans who immigrated from Armenia, 22.4\% have a "positive" attitude to this problem, 51.3\% - "negative", 26.3\% - "neutral". My interviews with this group of people have revealed that they are more concerned about the mastery of the English language than the purity of Armenian.

To sum up we can say that this sociolinguistic investigation gave us an opportunity to find out the ability of speakers of the Republic of Armenia as well as Armenian Diaspora to stand up to the pressure of more powerful language - English.

\section{References:}

1. Baker, C. (1988) Key Issues in Bilingualism and Bilingual Education. Clevedon, UK: Multilingual Matters.

2. Baker, C. (1992) Attitudes and Language. Clevedon, UK: Multilingual Matters.

3. Edwards, J. (1999) Refining Our Understanding of Language Attitudes. // Journal of Language and Social Psychology. N 18 (pp.101-110).

4. Garvett, P.; Coupland, N. \& Williams, A. (2003) Investigating Language Attitudes: Social Meanings of Dialect, Ethnicity and Performance. Cardiff: University of Wales Press.

5. Giles, H. \& Billings, A. (2004)Assessing Language Attitudes: Speaker Evaluation Studies. // Handbook of Applied Linguistics (pp.187-209). / Ed. by A. Davies \& C. Elder Oxford: Basil Blackwell.

6. Hudson, R.A. (1980) Sociolinguistics. Cambridge University Press.

7. Lasagabaster, D.; Huguet, Á. (2007) Multilingualism in European Bilingual Contexts: Language Use and Attitudes. Clevedon: Multilingual Matters.

8. McKenzie, R.M. (2010) The Social Psychology of English as a Global Language: 
Attitudes, Awareness and Identity in the Japanese Context. Berlin: Mouton de Gruyter.

9. Mey, J.L. (2009) Concise Encyclopedia of Pragmatics. Elsevier Ltd, UK.

10. Ryan, E.B. \& Giles, H. (Eds.) (1982) Attitudes Towards Language Variation: Social and Applied Contexts. London: Edward Arnold.

11. Stockwell, P. (2002) Sociolinguistics: A Resource Book for Students. Routledge.

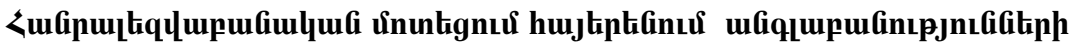 lppunnıpjufi jufinphi}

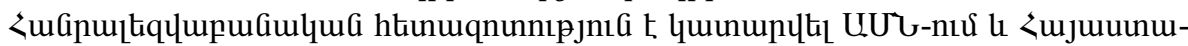

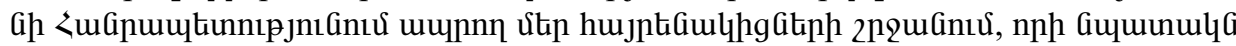

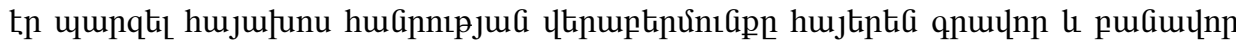

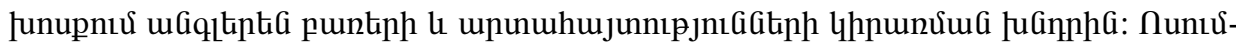

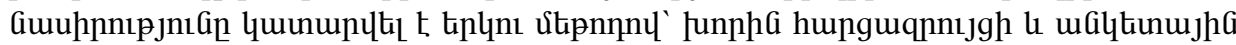

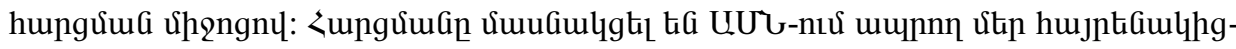

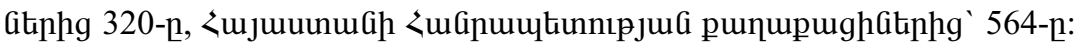

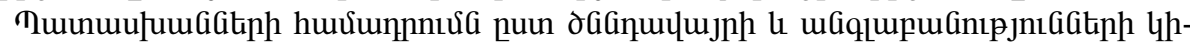

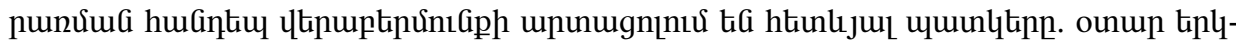

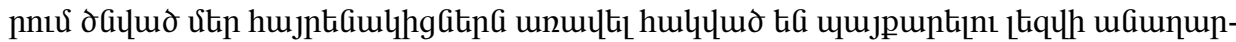

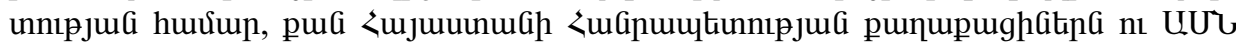

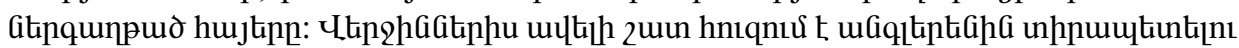

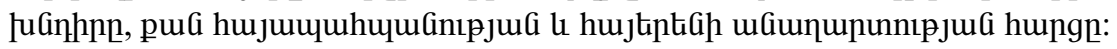

